\title{
The Collective Mental State Examination as Predictive Tool for Assessing Unfavourable Political Outcomes
}

\author{
William Walter Bostock
}

\begin{abstract}
The purpose of this article is to establish that the mental state examination, a fundamentally important part of individual psychiatric examination, also has a role to play in the diagnosis of situations that could have potentially harmful political outcomes for whole societies. This is because societies operate through a collective mental state which is in a state of constant variability and at times can present a situation of extreme vulnerability. Political leaders of an infinite range of intentions can work through the collective mental state to mine the bedrock of collective consciousness, where national identity resides, to produce outcomes that can hugely range from beneficial to disastrous.
\end{abstract}

Key words - collective consciousness, collective mental state, identity, mental state examination, mental state disorder.

\section{INTRODUCTION: THE MENTAL StATE EXAMINATION (MSE)}

The Mental State Examination (MSE) is an essential and fundamental part of every mental health assessment but is not to be confused with the Mini-Mental State Examination (MMSE) which is a neuropsychological screening test for dementia and other disorders.

Though not rigidly structured, it is generally agreed to consist of eight components. These are:

1) Appearance and Behaviour, covering physical appearance and presentation, physical distance separation, eye contact, facial expression, familiarity, or defiance.

2) Speech: from talkative to mute, including volume, tone, and fluency.

3) Mood: predominant emotion, for example, euthymic, dysphoric, apathetic, angry,

or explosive.

4) Affect: current observed and expressed emotional state, ranging from constricted to labile, and appropriateness of affect.

5) Thought: a thought stream, as either racing or restricted, the form of thought as goal directed and disordered.

6) Perception: this could be by depersonalisation, derealisation, or other delusion.

7) Cognition: firstly, the level of consciousness, such as alert or stupefied, awareness or confusion; memory, as immediate, short term, or long term, with ability to recall.

8) Insight and judgement: ability to identify and classify events; ability to make judgements as to likely outcomes of actions [1].

The question now arises as to whether the MSE has a valid application with groups, collectivities, whole societies or even nations?

\section{THE FUNCTIONING OF SOCIETIES}

Societies operate at a conscious level which has been called the collective consciousness. The existence of a consciousness, which at any one time is a mental state, possessed by a group, crowd, community or whole society (a collectivity), over and above the sum of individual consciousnesses, as has been asserted by many famous writers. Le Bon [2] observed that in crowds a collective mind emerged and possessed a life of its own. Freud accepted the concept of the group mind but considered that Le Bon had underestimated the role of leadership [3]. Durkheim discussed in depth the concept of the collective consciousness [4], and Halbwachs introduced the concept of the collective memory [5].

However, this hypothesis is controversial and psychiatric literature reflects this controversy. Folie à deux has been recognised since the late nineteenth century as a condition passed by contagion as an induced psychotic disorder between two people such as siblings or spouses. However, in the Diagnostic and Statistical Manual of Mental Disorders (DSM-5) [6], the Shared Psychotic Disorder (Folie à Deux) is not considered as a separate entity, leaving the diagnostician to classify the secondary patient as "Delusional Disorder" or "Other Specified Schizophrenic Spectrum and Other Psychotic Disorder".

Collective consciousness, if accepted, can therefore be seen as the totality of thoughts, messages, often in the form of narratives, coexisting with the full gamut of emotions, based on memories, real or distorted within a human grouping, while the collective mental state can be seen as a snapshot of the collective consciousness at a particular point in time.

As well as uncertainty in the psychiatric literature, there is also philosophical denial that collective mental states exist, a position which has been called Methodological Individualism. This position argues that all behaviour must be reduced to the behaviour and actions of individuals, and is a view associated with Schumpeter, Popper, and more recent theorists [7]. At its basis, the problem with isomorphism between individual and collectivity lies the fact that health or ill-health of an individual is easy to objectively recognise, while that of a collectivity is subject to value judgement. 
In addition to debate over collective thought processes, there has also been debate over the existence of collective emotions. The existence of genuinely collective emotions has been the subject of philosophic debate. For example, Tollefsen argued that groups can be the legitimate bearers of individual mental states which they share [8] while Szanto has asserted that it is possible for a group of individuals to literally share a single mental unit, which he calls a zombie conception of group minds [9].

A related topic is whether genuinely collective emotions can exist, or whether shared emotions are simply aggregates. Huebner considered this question from a philosophical point of view, and came to the conclusion that genuinely collective emotions can exist, given a certain level of organisation [10].

Collective consciousness can therefore be seen as a stream of the totality of thoughts, messages, verbalisations and narratives, co-existing with a full gamut of emotions, based on memories, real or imagined, of existence within the collectivity, and will be possessed at any point of time, as a collective mental state. At the foundation of collective consciousness, and the source of its continuity, in the view of many theorists, lies identity.

\section{III. IDENTITY}

In the approach of psychoanalysis as developed by Freud, identity was seen as the basis of the socialisation process by which individuals are moulded. Freud stated that "(I)dentification is known to psychoanalysis as the earliest expression of an emotional tie with another person..." [11]. Identification was seen by Freud as a developmental process by which a child would perceive themself through interaction with a parent. This theme was developed by the psychologist Erikson when he asserted that a strong sense of identity is a fundamental part of both a successfully functioning individual and for a society as a whole, thus leading to the concept of the collective consciousness which at any point of time will be a collective mental state. He also observed that in a collectivity, the states of confusion, crisis and panic are created by a weak or confused sense of identity. Erikson went on to state that when identity is not well-integrated, strongly negative emotions may emerge, which, in his words, may arouse a "murderous hatred of 'otherness"' [12].

In more recent times, identity has been conceptualised as a mental state of continuous, internal, subjective awareness of self [13], which may occur in either an individual or as a group, community or larger collectivity. Therefore, it can be said that a robust and well-integrated sense of identity is essential to successful functioning and continued existence.

A theory of social identity has been developed by Tajfel and others whereby an individual identity has a social dimension based on group membership, in a process which creates in-groups and out-groups, leading to negative thoughts and conflict [14]. The connection between collective behaviour and intergroup aggression has also been explored by Faturochman [15].

Collective identity in artistic representation has a long history. It is clear that many novelists, poets and other artists have given expression to their feelings of identity throughout their work. Some prominent examples include the writer Cervantes who helped to define Spanish identity, the romantic poet Adam Mickiewicz who gave rise to a new form to Polish identity, the writer and political activist Jose Riza, who was a powerful influence in forming Philippine identity, particularly after his death, and Marcel Proust, the French writer who explored the relationship between memory and identity. The input could be poetry and music, as for example in Smetana's Ma Vlast- My Country, which has helped to shape Czech identity [16], or in a painting, such as The Scream by Norwegian artist Edvard Munch, which has helped to shape feelings of existential crisis of the individual. At a conceptual level, Marx used identity theory when he conceptualised class consciousness, and many political leaders of all ideological positions have attempted to create and exploit collective identity amongst the governed individuals.

The importance of the integration of the sense of identity was stated by Antonovsky when he developed the concept of the sense of coherence. Specifically, Antonovsky saw a key role of an individual's sense of coherence in the maintenance of health. The sense of coherence is defined as a "global orientation that expresses the extent to which one has a pervasive, enduring though dynamic feeling of confidence that one's internal and external environments are predictable and that there is a high probability that things will work out as well as can be reasonably expected." [17]. The concept of sense of coherence is also exhibited at a collective level whenever a sense of group consciousness exists, hereby giving an insight into the importance of internal integration in the state of consciousness. In confirmation of this, Eriksson and Lindstrom noted that under conditions of extreme stress, the sense of coherence can be severely compromised [18].

The concept of identity has its critics. For example, Brubaker and Cooper argue that the term is so constructed, fluid and multiple that it is analytically useless. They note the large range of identifications that are available in today's society, such as gender, sexuality, race, religion, ethnicity, nationalism, immigration, new social movements, and culture and ask: can all of these be the basis of identity politics"? Collective identity is, as Brubaker and Cooper note, a multifaceted concept which exists at a subjective level as morale, esprit de corps, or in-group feelings of affection such as brotherhood or sisterhood and can be based on narrative or legend as seen in indigenous populations., though in this sense, it is argued, that the concept is not irrelevant but rather it is full of insight [19].

In opposition to this, one can visualise collective identity as: a process of collective self-awareness; possession of boundaries; belief in continuity in space and time; the act of being in communication both internally and externally; transacting with the internal and external world with selfawareness; self-appraisal of performance; possessing a feeling of responsibility for actions carried out collectively and individually and holding others responsible; with the result being successful adaptation and survival [20].

National identity, a political example of collective identity, has been studied by anthropologists as "national character". Political scientists have emphasised the importance of national identity in achieving state stability, especially in post-colonial nation-states. The concepts of national identity and state stability are conceptually analogous to the mind/body relationship, in that a strong sense of national identity is a necessary condition of a state that is facing a 
threat [21]. In another conceptualisation, identity is based in memory, therefore the possession of memories and emotions that can be drawn upon in a similar way that capital is in an economic context at a collective level as well as an individual level, is a characteristic of a collective mental state [22].

Some research is currently investigating the neurobiology of interpersonal functioning using neuro-imaging. This approach is investigating the degree of similarity/dissimilarity of neural signals between multiple interacting brains. Using this technique, it will be possible to identify the neural correlates of a collective mental state. Thus, the current work of neuroscientists on the transmission of neuro-signals between individual brains can be interpreted as giving confirmation to the concept that a mental state can be shared. Moreover, the communication of emotion is the most important process for the purpose of mental health [23].

\section{The COMPONENTS OF A MENTAL State Examination FOR COLLECTIVITIES}

The eight components of the individual mental state examination could be distilled into a four component MSE for a collectivity. The components could be:

1) Level of Functioning. How is the collectivity functioning economically, healthily, physically politically and non-violently, within its environment?

2) Mood. To what extent is the collectivity subject to widespread gloom and depression, or at the other extreme, unfounded and unrealistic and therefore short-term elation?

3) Thought Coherence. Is the stream of expressed thought coherent, realistic, and grounded, with internal and external threats of conflict soundly managed?

4) Perception of Identity. Is there a strong and viable sense of identity which is based on sound and realistic assessment of the past, the present, the future and realistic grasp of external perceptions?

An examination of the mental state of a collectivity could enable an assessment of the future development of that collectivity and its response to the exigencies of survival as either ordered or disordered, and an assessment of vulnerability to noisome or even toxic leadership.

\section{Disorders of the COLlective Mental State}

It thus becomes clear that an examination of the collective mental state can indicate the presence or future presence of a disorder, that is, when its functioning is severely disrupted to the extent that it is outside the parameters of a normal range of behaviours. Specifically, when breakdown of basic servicing has occurred, when mood is severely depressed, when thought and speech are majorly disturbed to the extent of being disabling, when rage leads to pro-active war, aggression to ethnic cleansing, violence, and genocide, and when perception is so distorted as to undermine rationality. There is also a positive side to a disordered collective mental state, coming from the concept of "collective intelligence", where the intelligence provided by a group is qualitatively superior to that of individuals [24].

Some major types of disorder that the collective mental state examination could identify are:
1) Disruption of Functioning. The failure to provide the physical necessities of life through economic, natural, or political shortcoming will be reflected in the MSE as a contagion of fear. Fear can be felt by a large number of people, particularly when it is communicated consciously and unconsciously. A state of generalized anxiety can develop as a prelude to fear and can be created by political leaders who are disposed to do so. Lake and Rothchild developed this observation:

"As groups begin to fear for their safety, dangerous and difficult-to-resolve strategic dilemmas arise that contain within them the potential for tremendous violence...Ethnic activists and political entrepreneurs, operating within groups, build upon these fears of insecurity and polarise society." [25].

The insight here is that leaders can create outcomes by mobilising bystanders through the mining of their grievances Here real or imaginary victimhood can play an important role. Collective fear can lead to violence through a belief in preemptive violence [26].

The transformation of individuals, families, and communities from peaceful orientation into perpetrators of violence through the use of collective fear is a phenomenon that has been observed on many occasions by many writers as well as those mentioned above. An example of this was when Hitler developed and exploited the collective mental state of fear among the German population of the advancing Soviet Red Army and was thus able to prolong World War 2.

2) Disorder of Mood. Exogenous and endogenous conditions can be associated with the development of depression and reinforced sense of victimhood in individuals, and this can lead to a loss of belief including belief in a future [27]. Depression in individuals can lead to a sense of hopelessness which can become widespread so that one could refer to depression that is collective.

Depression can, in another view, be a result of a condition of learned helplessness, which can arise when undeserved punishment is inflicted on an individual, and this can be passed to others by contagion [27].

While there is on-going debate over the philosophical status of the concept, some modern theorists treat collective depression as an aggregate of states of depressions among individuals. Kesner sees the insufficient grasp of the relationship between individual and collective mental pathologies as one of the major challenges of contemporary psychiatry. Here he highlights the role of public (material) representations in this process and observes that, for example, media amplification of traumatic disaster news generates anxiety symptoms, stress disorders, and other psychopathologies [28].

Depression is difficult to quantify, but in the United States, The National Comorbidity Survey Replication study assessed the DSM-IV major depressive disorder (MDD) and assessed work impairment with the WHO Health and Work Performance Questionnaire (HPQ). The prevalence rate for MDD was $6.4 \%$ in the previous 12-months additionally, annual human capital loss per ill worker was estimated at $\$ 4426$ for the disorder. Annual projections to the US labour force were \$36.6 billion for MDD [29].

The burden of collective depression is highly pervasive in the developing world. Many people, particularly young adults 
in affluent societies could be considered as showing symptoms of depression. The occurrence of collective depression created by regimes perceived as unfavourable or degrading creates instability because of the risk of entailing even worse regimes. Organization theory may make a contribution here as certain types of leadership can have "toxic effects" on organizational motivation [30].

3) Disorder of Thought and Speech. The sources of aggression-provoking thought, and speech have long concerned psychologists, social scientists, and philosophers, particularly when, if allowed to develop, they can take the form of unprovoked war. War can take the form of open armed conflict between sovereign states or civil war with a state. Also, within a state there can be a war of secession motivated by fear, or grievance over land, culture, language, religion or ideology. There can also be wars of independence between those seeking autonomy and an occupying state such as a colonizing power.

In civil war, such as the American Civil War (1861-1865), war was mechanized and the loss of life was very great, in fact higher than that of Americans in World War 2. In the Spanish Civil War (1936-1939) where the loss of life was also great, and even today, resentments are still felt by some descendants of participants. The American Civil War was about issues of race and central government, while the Spanish Civil War concerned issues of religion, land ownership and regional autonomy for Catalonia and the Basque Country, with some sympathy in Galicia. In the English Civil War (1642-1648), the issue was monarchy and change. Often the central issue in a civil war is identity, as expressed in difference of language and culture but whose expression is frustrated. The civil war in Sri Lanka (19832009) is an example of this [31]. All of the above-mentioned civil wars could be described as reflecting a disordered collective mental state.

Aggressive thought and speech can include collective memories and interpretations of traumatic events of a long past time, particularly where a concept of victimhood is invoked [26]. In 1389 in the Battle of Kosovo, Islamic invaders took conquest of the Balkans, with the result that justifications for the conflict between Serbians and Kosovars, who are predominantly Islamic, in 1998.

In his discussion of the disintegration of the former Yugoslavia, Kis concluded that a fervent belief in nationalism was the predominating causal factor. He diagnosed a state of collective and individual paranoia, describing collective paranoia as a combination of many individual paranoias, reaching a paroxysm in a group whose goal is resolve an issue of absolute importance, namely, the survival of the nation [32]. In this way, aggressive hyper-nationalism can be interpreted as a disorder of thought and speech impacting upon the collective mental state.

4) Disorder of Perception. Collective aggression can also follow the widespread dissemination of a perception affecting certain strata of society such as specific groups, communities, nations and even continents, of the need to take revenge, which can lead to genocide. A single event such as the assassination of a political leader can provide the trigger to release an outburst of collective violence leading ultimately to war or genocide. The shooting-down in 1994 by stillunknown persons of the aircraft carrying the President of
Rwanda, Juvenal Habyarimana, was followed immediately by a genocidal attack on Tutsis by the majority Hutus, a clear example of collective aggression [26].

\section{POLITICAL OUTCOMES}

In a study of collective violence, it has been observed that severe changes to the social and political milieu can result in the outcome of an acceptance of violence becoming common in a process of desensitization. As Borkenau expressed it:

"Once the carapace of custom is disrupted, the process acquires the characteristics of a chain reaction. Every rift opened by the devaluation of rules widens automatically and produces new rifts in other places .... conduct becomes more and more irrational, the area of moral uncertainty is constantly widening, until the typical situation of the "dark ages," a situation of total insecurity and universal crime, is reached [33].

When a collectivity experiences widespread violence, it is a serious disorder that can develop into genocide. Killing can be interpreted as healing, as in suicide, and killing others can be interpreted as therapeutic, healing, as in collective euthanasia. This is the case with wars of extermination, where whole categories of people are intended to disappear by genocide. The war of extermination may be disguised as resettlement, as in the Black War in Tasmania, or it may be large scale, as in the Third Reich where a number of categories of people were slated for disappearance or Cambodia under the Pol Pot regime (1975-1979), which has been described as an autogenocide in that Cambodians themselves were the target group [34].

Thus, it can be hypothesized that a collective mental state can by contagion create aggression that can be allowed to develop through comprehensive collective desensitization to violence. The implementation of policies leading to suicidal, homicidal, or genocidal acts and other atrocities including mass rape and mass mutilation are outcomes revealing that the common factor of a disordered collective mental state is present, providing the opportunity for manipulation by leader or groups [35].

\section{CONCLUSION}

The examination of a collective mental state can indicate the presence of a potential disorder which can profoundly affect the future path of a human society. The vulnerability created by the presence of disorder at the collective level can provide an opportunity for a leader so disposed to exploit this situation and in so doing produce outcomes that are truly catastrophic, such as war, genocide, and devastation through generalised violence.

Thus, the examination of the collective mental state can provide a predictive tool which can be used by transdisciplinary specialists from psychology, psychiatry, philosophy, linguistics, and social sciences such as political science, enabling them to work on addressing the great issues facing humankind. This they can do by recognising and assessing the symptoms of danger in a collective mental state and any underlying instabilities of identity, and in so doing, take steps to circumvent catastrophe. 


\section{REFERENCES}

[1] B. K. Puri, P. J. Laking, and I. H. Treasaden, I.H., Textbook of Psychiatry. Edinburgh, London, New York, Philadelphia, Sydney, St Louis, Toronto: Churchill Livingstone, 1996.

[2] G. Lebon, The Crowd: A Study of the Popular Mind, (First published 1895), London: Sparkling Books, 2008.

[3] S. Freud, Group psychology and the analysis of the ego, London: The International Psycho-Analytical Press, 1922.

[4] E. Durkheim, The rules of sociological method. 1964, New York: Free Press and London: Collier-Macmillan, 1964.

[5] M. Halbwachs, On Collective Memory, Chicago: University of Chicago Press, 1992.

[6] American Psychiatric Association, (APA), Diagnostic and Statistical Manual of Mental Disorders, (DSM-5). APA-Press, Washington, DC, 2013.

[7] A. Sabiescu, The Issue of Collective Agency in Community-based Open Content Creation. Proc. IDIA, 2011, pp. 140-159.

[8] D. P. Tollefsen, From extended mind to collective mind. Cognitive systems research, vol. 7, no. 2-3, pp. 140-150, 2006. https://doi.org/10.1016/j.cogsys.2006.01.001

[9] T. Szanto, How to share a mind: Reconsidering the group mind thesis. Phenomenology and the Cognitive Sciences, vol. 13, no. 1, pp. 99-120, 2014. DOI:10.1007/s11097-013-9323-1

[10] B. Huebner, Genuinely collective emotions. European Journal for Philosophy of Science, vol. 1, no. 1, pp. 89-118, 2011. DOI: 10.1007/s13194-010-0006-2.

[11] S. Freud, Beyond the pleasure principle. In The Standard Edition of the Complete Psychological Works of Sigmund Freud, Vol. XVIII (19201922): Beyond the Pleasure Principle, Group Psychology and Other Works, London: Hogarth, pp. 1-6, 1955.

[12] E. H. Erikson, 'Identity, Psychosocial', in D.R. Sills, ed., Encyclopedia of the Social Sciences. New York: Macmillan and Free Press, vol. 4 , pp. 61-6, 1968.

[13] A. S. Reber, Arthur S., The Penguin Dictionary of Psychology (2nd edition). London, New York, Ringwood, Toronto, Auckland: Penguin, 1995.

[14] H. Tajfel, J. Turner, W. G. Austin, and S. Worchel, (1979). An integrative theory of intergroup conflict. Organizational identity: A reader, 56, 65, 1979.

[15] Faturochman, Collective Behaviour and Intergroup Aggression. Buletin Psikologi vol. 7, no. 2, pp. 1-6, 1999. DOI: 10.22146/bpsi.7403.

[16] R. Fidler, The Golden Maze, A Biography of Prague, Sydney, ABC Books, 2000.

[17] A. Antonovsky, Health, Stress and Coping. San Francisco, London: Jossey Bass, 1980.

[18] M. Eriksson, and B. Lindström, Antonovsky's sense of coherence scale and the relation with health: a systematic review. Journal of epidemiology \& community health, vol. 60, no. 5, pp. 376-381.

[19] R. Brubaker and F. Cooper, Beyond identity", Theory and Society, vol 29 , pp. $1-47$.
[20] M. Brewster Smith, Self and identity in historical/sociocultural context: "Perspectives on selfhood". In Y. Kashima, M. Foddy, \& M. J. Platow (Eds.), Self and identity: Personal, social, and symbolic, pp. 229-243. Mahwah: Lawrence Erlbaum Associates Publishers, 2002.

[21] W. W. Bostock and G. W. Smith, On Measuring National Identity. Social Science Paper Publisher, vol. 4, no. 1, pp. 1-6, 2001. http://eprints.utas.edu.au/788/.

[22] K. E. Boulding, The Economics of The Coming Spaceship Earth., The Earthscan Reader in Environmental Economics. In H. Jarrett (ed.) Environmental Quality in a Growing Economy, pp. 3-14. Baltimore, MD: Resources for the Future/Johns Hopkins University Press, pp.2735, 1992. http://dieoff.org/page160.htm.

[23] D. Ray, D. Roy, B. Sindhu, P. Sharan, and A. Banerjee, Neural substrate of group mental health: Insights from multi-brain reference frame in functional neuroimaging. Frontiers in psychology, vol. $8, \mathrm{p}$. 1627, 2017. DOI: 103389/fpsyg.2017.01627.

[24] F. Heylighen, Collective Intelligence and its Implementation on the Web: algorithms to develop a collective mental map. Comput Math Organ Theory, Vol. 5, no.3, pp. 253-280, 1999.

[25] D. A. Lake, and D. Rothchild, Containing fear: The origins and management of ethnic conflict. International Security, vol. 21, no. 2 , pp. 41-75, 1996.

[26] D. Bar-Tal, L. Chernyak-Hai, N. Schori, and A. Gundar, A., A sense of self-perceived collective victimhood in intractable conflicts. International Review of the Red Cross, vol. 91, no. 874, pp.229-258, June 2009.

[27] R. Haig, The Anatomy of Grief. Springfield, Charles Thomas, 1990.

[28] L. Kesner, Mental Ill-Health and the Epidemiology of Representations. Frontiers in Psychiatry, vol. 9, no. 289, pp. 1-6., 2018 https://doi.org/10.3389/fpsyt.2018.00289.

[29] R. C. Kessler, K. McGonagle, S. Zhao, C. B. Nelson, M. Hughes, S Eshleman, H.-U. Wittchen, and K.S. Kendler. "Lifetime and 12-month prevalence of DSM-III-R psychiatric disorders in the United States: results from the National Comorbidity Survey." Archives of general psychiatry, vol. 51, no. 1, pp.8-19, 1994.

[30] L. Hirschhorn, Leaders and followers in a postindustrial age: A psychodynamic view. The Journal of Applied Behavioral Science, 1990. vol. 26, no. 4, pp. 529-542, 1990.

[31] W. W. Bostock, Language grief: A 'raw material'of ethnic conflict Nationalism \& Ethnic Politics, , 1997. Vol. 3, no. 4, pp. 94-112, 1997.

[32] D. Kis, On nationalism. Performing Arts Journal, Vol. 18, no. 2, pp. 13-16, 1996

[33] F. Borkenau, End and Begining, on the Generations of Cultures and the West. New York: Columbia University Press, 1981.

[34] E. Staub, The Roots of Evil, The Origins of Genocide and Other Group Violence. Cambridge: Cambridge University Press, 1992

[35] M. Gallo and C. Economy, Crowds, Riots, and Collective Violence. In R.W. Summers, ed., Social Psychology: How Other People Influence Our Thoughts and Actions, Santa Barbara, Denver: Greenwood ABCCLIO, pp. 385-408, 2016. 